\title{
Congenital trigeminal neuropathy in oculoauriculovertebral dysplasia-hemifacial microsomia (Goldenhar-Gorlin syndrome) ${ }^{1}$
}

\author{
S. ALEKSIC, ${ }^{2}$ G. BUDZILOVICH, R. REUBEN, I. FEIGIN, M. FINEGOLD, \\ J. McCARTHY, S. ASTON, AND J. M. CONVERSE \\ From the Department of Neurology-Pediatric Neurology, Pathology-Pediatric Pathology, \\ and Laboratory of Neuropathology and Center for Craniofacial Anomalies, Institute for Plastic and \\ Reconstructive Surgery, New York University-Bellevue Hospital Medical Center, New York, N.Y., U.S.A.
}

\begin{abstract}
SYNOPSIS A $2 \frac{1}{2}$ year old child with clinical features of Goldenhar-Gorlin syndrome showed diminished pinprick sensation over the right half of the face. After surgery for the cleft lip, the child died. Neuropathological investigation showed agenesis of the right trigeminal nerve and hypoplasia of the right trigeminal brain-stem nuclei. Nosological aspects of the Goldenhar-Gorlin syndrome and previously reported cases of congenital trigeminal anaesthesia in this disorder are discussed. It is suggested that the hypoplasia of the trigeminal nerve is responsible for the diminished facial sensation seen in some patients with this craniofacial syndrome.
\end{abstract}

Congenital trigeminal anaesthesia has been recorded in several patients with clinical findings of oculoauriculovertebral dysplasia-hemifacial microsomia (Goldenhar-Gorlin syndrome). The exact site and nature of pathological findings in such cases has been unknown. Recently, we had the opportunity to examine a child with clinical features of Goldenhar-Gorlin syndrome who died after operation. Examination of the brainstem revealed unilateral aplasia of the trigeminal nerve and corresponding brain-stem nuclei.

\section{CASE REPORT}

R.Y. was a $2 \frac{1}{2}$ year old girl who was admitted to the hospital for correction of cleft palate in March 1973. She was born after a nine month pregnancy which was uneventful except that her mother took some unidentified antiemetic pills for vomiting early in the course. There was no family history of congenital malformations, maternal radiation, or history of taking contraceptive pills. After delivery the child breathed immediately and Apgar score was 8 and 9

1 This work is supported in part by the grant of National Institute of Health, DEO no. 3568-01 A2.

2 Address for correspondence: Dr Aleksic, Bellevue Hospital, New York, N.Y. 10016, U.S.A.

(Accepted 22 May 1975.) at one and five minutes respectively. Examination revealed hypoplasia of the right side of the face, ipsilateral anophthalmia and anotia, preauricular skin appendages, lateral and midline cleft lip, cleft palate, and cervicothoracic scoliosis. Neurological examination was unremarkable except for defective movements of the right side of the face and diminished sensation to pin prick over the entire right half of the face. Radiography of the facial bones showed hypoplasia of the right half of the mandible, zygomatic bone, and orbit. The child was placed in an institution. At the age of $2 \frac{1}{2}$ years, she was readmitted to this Institute for reconstruction of cleft palate. Routine laboratory studies including chromosomal analysis were normal. Neurological examination revealed diminished pin prick sensation over the right half of the face, absence of speech, defective right facial movements, and mental retardation. After surgery for the cleft palate, the patient developed aspiration pneumonia and died two days after operation. The facial appearance of the patient about two months before death is shown in Fig. 1.

NEUROPATHOLOGICAL EXAMINATION The brain was removed about eight hours after death and fixed in formalin for about two weeks. Among other cerebral and brain-stem abnormalities there was a virtual absence of the right trigeminal nerve (Fig. 2). Serial 


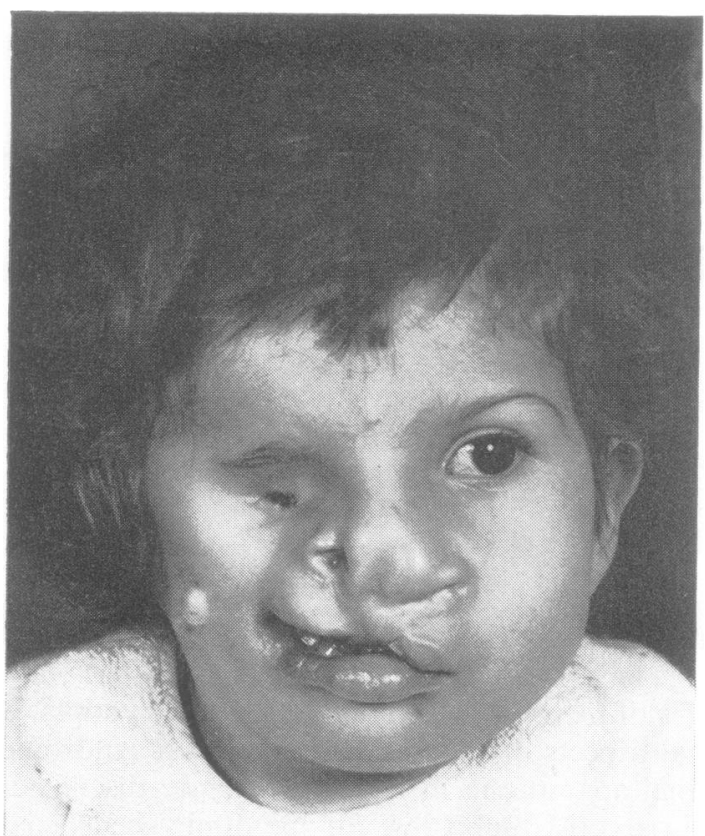

FIG. 1 Note the right-sided anophthalmia, clefting of the lip and nose, lateral facial cleft (macrostomia), hypoplasia of the soft tissues of the face, microtia, and preauricular appendages, all on the right side. sections of the brain-stem stained with various appropriate stains revealed absence of the right chief sensory and motor nuclei of the trigeminal nerve. The left trigeminal nerve and corresponding nuclei were normal.

\section{DISCUSSION}

The syndrome of oculoauriculovertebral dysplasia (Goldenhar's syndrome) consists characteristically of epibulbar dermoids, lid colobomas, auricular deformities and vertebral anomalies, hypoplasia of the soft and bony tissues of the face, and associated oral deformities. Incomplete syndromes are common in these patients (Gorlin et al., 1963). The dermoids and lipodermoids are the most common ocular deformities and are bilateral in about two-thirds of cases, while in about $25 \%$ of instances they may be absent. Other less common ocular anomalies include colobomas of upper eyelid, microcornea and microphthalmia, anophthalmia, colobomata of iris and choroid, iris atrophy and anterior polar cataract.

Bilateral auricular appendages, unilateral less commonly, and blind pretragal fistulas are the chief auricular signs of the syndrome. Microtia, deafness, with or without external auditory canal

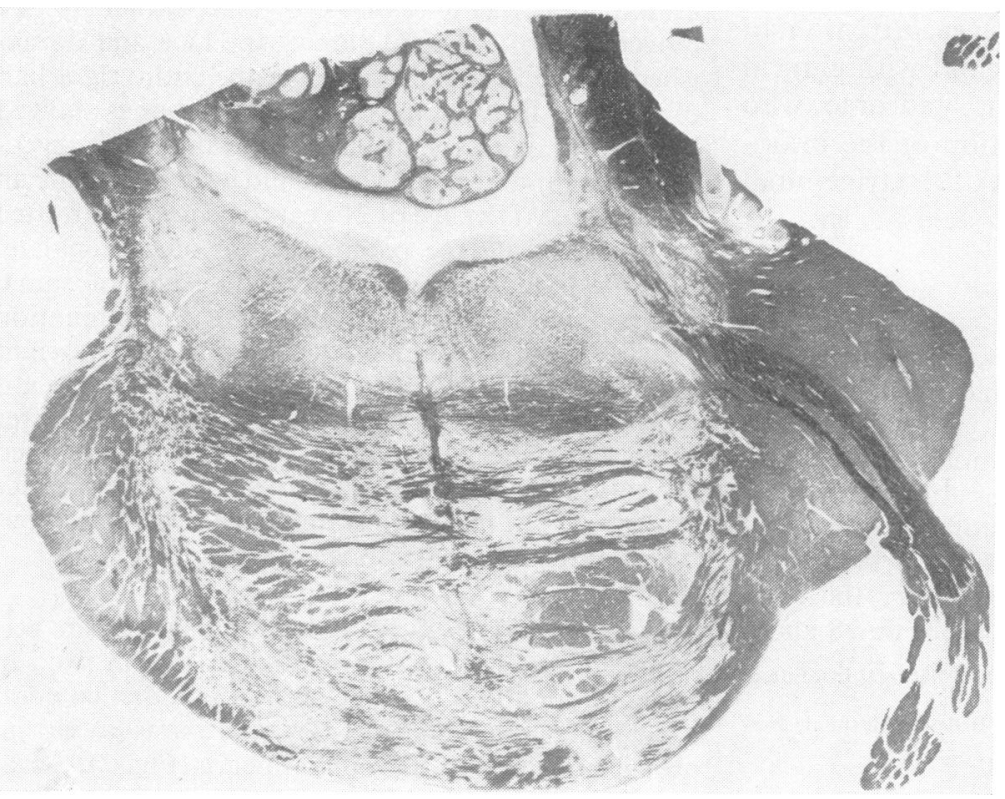

FIG. 2 Section of the pons at the level of the trigeminal nucleus and nerve. Left trigeminal nerve and nucleus are normal, while on the right side no corresponding structures can be seen. Myelin stain, $\times 15$ approximatcly. 
disturbances, are also common. Vertebral anomalies include hemivertebrae, anomalies of the atlas, cervical vertebral synostosis, spina bifida, and other less common disturbances.

Hemifacial microsomia - a term introduced by Gorlin and associates (1963) to designate unilateral hypoplasia of the facial soft and bony tissue with failure of formation of the mandibular ramus and condyle and ipsilateral microtia-was initially considered to represent a clinical entity distinct from the Goldenhar syndrome. Later, however, many transitional forms between the oculoauriculovertebral dysplasia cases and those of hemifacial microsomia have been encountered (Gorlin et al., 1971), clearly establishing the fact that hemifacial microsomia is simply a variant of the Goldenhar syndrome. The same applies to the cases of branchial arch syndromes, such as 'first arch syndrome' and 'first and second branchial arch syndrome' (Converse et al., 1973; Converse et al., 1974).

The loss of facial sensation and its practical importance has been documented previously in few instances of oculoauriculovertebral dysplasiahemifacial microsomia (Goldenhar-Gorlin syndrome) (Sugar, 1967; van Bijsterveld, 1969; Bowen et al., 1971 ; Budden and Robinson, 1973). Hypoplasia of the muscles of mastication with impaired muscle function is also noted in many of these patients, particularly involving the lateral pterygoid muscle and it may be seen in unilateral (Converse et al., 1973) and bilateral forms of this syndrome as well (Converse et al., 1974). The anatomical findings of our case suggest that hypoplasia of the trigeminal nerve represents an underlying pathological substrate for both the sensory and motor aspects of congenital tri- geminal neuropathy that has been previously noted in patients with the Goldenhar-Gorlin syndrome.

The authors wish to express their gratitude to $\mathrm{Dr} \mathrm{C}$. T. Randt, chairman, Department of Neurology, New York University, for support in completion of this work; to Mr R. Waldeck and Mr J. Cardona for the photographic material; to Mrs O. Mickle and Ms M. Atkins for help in preparation of slides and sections; to Ms P. King, secretary of the Craniofacial Study Project, and to Mrs C. Britt, secretary of the Laboratory of Neuropathology, for help in preparation of the manuscript.

\section{REFERENCES}

Bowen, D. I., Collum, L. M. T., and Rees, D. O. (1971). Clinical aspects of oculoauriculovertebral dysplasia. British Journal of Ophthalmology, 55, 145-154.

Budden, S. S., and Robinson, G. C. (1973). Oculoauricular vertebral dysplasia. American Journal of Diseases of Children, 125, 431-436.

Converse, J. M., Coccaro, P. J., Becker, M., and WoodSmith, D. (1973). On hemifacial microsomia. The firstand second branchial arch syndrome. Plastic and Reconstructive Surgery, 51, 268-279.

Converse, J. M., Wood-Smith, D., McCarthy, J. G., Coccaro, P. J., and Becker, M. (1974). Bilateral facial microsomia. Diagnosis, classification and treatment. Plastic and Reconstructive Surgery, 54, 413-423.

Gorlin, R. J., Červenka, J., and Pruzansky, S. (1971). Lateral facial cleft (macrostomia) with hemifacial microsomia and oculoauriculovertebral dysplasia (Goldenhar syndrome). In Birth Defects, Original Article Series, Vol. VII, No. 7, pp. 32-35, Third Conference on Delineation of Birth Defects, Part XI : Orofacial Structures. National FoundationMarch of Dimes. Edited by D. Bergsma. William and Wilkins: Baltimore.

Gorlin, R. J., Jue, R., Jacobsen, K., and Goldschmidt, E. (1963). Oculoauriculovertebral dysplasia. Journal of Pediatrics (St. Louis), 63, 991-999.

Sugar, H. S. (1967). An unusual example of the oculoauriculovertebral dysplasia syndrome of Goldenhar. Journal of Pediatric Ophthalmology, 4, 9-12.

Van Bijsterveld, O. P. (1969). Unilateral corneal anesthesia in oculoauriculovertebral dysplasia. Archives of Ophthalmology (Chic.), 82, 189-194. 